MEIYING JIAN, Ph.D. Candidate ${ }^{1,2}$

E-mail: jianmy321@163.com

JING SHI, Ph.D. ${ }^{1}$

(Corresponding author)

E-mail: jingshi@mail.tsinghua.edu.cn

YANG LIU, Ph.D. Candidate ${ }^{1}$

E-mail: Iy3664296@126.com

1 Department of Civil Engineering, Tsinghua University

Beijing 100084, China

2 School of Transportation, Inner Mongolia University

Hohhot 010021, China
Traffic in the Cities

Preliminary Communication

Submitted: 22 Dec. 2016

Accepted: 10 Oct. 2017

\title{
DEPENDENCE OF THE FUTURE ELDERLY ON PRIVATE CARS: A CASE STUDY IN BEIJING
}

\begin{abstract}
With the aging of population in the world, understanding the travel demands of the elderly is important. In China, the aging society is in the process of forming. Meanwhile the urban motorization has just started. The aim of this paper is to investigate the dependence of the future elderly on private cars. The data used here come from a stated preference (SP) survey of the young and middle-aged residents in the capital of China, Beijing. The influencing factors on the car ownership and mode choices of the future elderly are analysed based on the ordered logit model and MNL model, respectively. The effect of uncertainty in respondents' statements on the car usage has been also investigated. The results show that the future elderly in Beijing become increasingly dependent on private cars. It is also found that younger people have higher propensities to own private cars and to make use of driving after the age of 65. Moreover, improving public transport services contributes to an increased ridership of public transport by the future elderly. The findings in this paper can provide valuable references for the aging society when making transport policies in Beijing.
\end{abstract}

\section{KEY WORDS}

travel demand; the future elderly; car ownership; mode choice; influencing factors;

\section{INTRODUCTION}

The world population is aging. People aged 65 or above accounted for $8.27 \%$ of the world's total population in 2015 [1]. This percentage is projected to increase up to $14 \%$ by 2040 [2, 3]. With the aging of population, issues in life quality of the elderly are of great concern. Compared with working-age people who had been primarily concerned in previous studies, the elderly have put the distinct requirements on transportation systems, due to their deteriorating psychological and physical functions, smaller financial resources as well as more leisure time [4, 5]. Meeting the special travel demands of the elderly can increase their activity participation rates. High activity participation rates are always an indicator of the better quality of life [6]. As a result, investigating the travel demands among the elderly can help to improve their quality of life and eventually avoid social exclusion [7].

It is found that the elderly in Western counties become more and more dependent on private cars [711], and this dependence is much higher among the elderly who own private cars [12]. However, for the elderly in Beijing, the capital of China, only $1.58 \%$ of their trips are performed by private cars [13]. This is probably because the urban motorization in China has just started, and the car ownership of the elderly at present is relatively low. But as the urbanization and motorization continuously advance, the travel characteristics of the elderly in Beijing will change dramatically. It is often believed that the future elderly in Beijing will become increasingly dependent on private cars, and the aim of this paper is to test this prediction from two aspects: car ownership and mode choice behaviours of the future elderly.

The existing studies have shown that lots of factors influence the mode choice behaviours of the elderly, such as personal characteristics, accessibility of public transport, neighbourhood, environment, land-use, etc. Kim and Ulfarsson [14] investigated the mode choice behaviours of the elderly in Washington State. They found that income and car ownership are positively associated with the elderly's propensities to drive a car, but negatively related with their propensities to use public transport. Later, this finding was confirmed by the study of Schmöcker et al. [12] which investigated the shopping trips of the elderly in London. Moniruzzaman et al. [15], using data from 2008 Montreal's Household Travel Survey, found that the elderly with the lowest income are more likely to make their trips by walking. Furthermore, other studies pointed out that the effect of the bus service frequency is not 
significant, but the bus stop density has a significant influence on the share of public transport $[12,16]$. Su et al. [17], concentrating on the mode choices of the elderly before and after shopping, found that travel cost of driving are negatively associated with the elderly's propensities of driving a car. By comparing the individual's travel behaviour between the elderly and people aged 19 60, Zhang et al. [13] found that the differences between them increase with the age of the elderly.

Clearly, the existing studies mainly focused on the revealed mode choice behaviours among the elderly, but a comprehensive investigation on their travel demands is relatively scarce. Since an individual's travel behaviour is always affected by transportation systems, differences often exist between the revealed travel behaviours and their demands. Furthermore, little attention has been paid to the travel demands of the future elderly so far, which are important references for allocating limited transportation resources and formulating proper transport policies. As information about the travel demands of the future elderly are not available, this paper investigates the car ownership and mode choices of the future elderly, based on the data coming from a stated preference (SP) survey of the current young and middle-aged people. Previous studies have shown that shopping is the most frequent activity of the elderly [17]; thus the focus of this paper is on the mode choices for shopping trips. This paper tries to deepen the understanding of the travel behaviours of the elderly and related influencing factors, which are helpful to construct better transportation systems and policies, to reduce social exclusion and to increase the social welfare. Therefore, the task of this paper is important for both the elderly and the society.

\section{METHODOLOGY}

\subsection{SP survey}

The SP survey, known as a discrete choice experiment, can collect data about behavioural responses to choice situations that do not exist on the current real market [18]. This method is widely used to analyse the preferences and/or anticipated choice behaviours in transportation. As revealed preference (RP) data are not available when modelling the choice behaviours of the future elderly, this paper relies on an SP survey to collect data about car ownership and mode choice behaviours among the future elderly.

Obviously, the outcome variable of the car ownership among the future elderly is discrete and ordinal; therefore, it is more appropriate to employ the ordered logit model. With regard to mode choice behaviours of the future elderly, the choice set consists of more than two alternatives, and the multinomial logit (MNL) model is used.

\subsection{Ordered logit model}

In the ordered logit model, the decision processes that an individual faces are ordinal (e.g. how many private cars should I own after the age of 65?), and the alternative number of private cars is assumed to be associated with a latent utility which is divided as

$U_{n}=V_{n}+\varepsilon_{n}=\beta^{\prime} X_{n}+\varepsilon_{n}$

where $U_{n}$ denotes the latent utility of individual $n ; \boldsymbol{X}_{n}$ denotes a vector of personal characteristics; $V_{n}$ is the systematic component; $\beta$ means the vector of the corresponding coefficients which have to be estimated; $\varepsilon_{n}$ is the error term which captures all unobserved factors. Here, the error term $\varepsilon_{n}$ is assumed to follow logistic distribution [19].

Thus the assumption of independent errors for each alternative in the logit model does not hold here, and the car ownership decision is made by individual $n$ as follows:

- If $U_{n}<u_{1}$, then individual $n$ intends to own no car after the age of 65

- If $u_{1}<U_{n}<u_{2}$, then individual $n$ intends to own one car after the age of 65

- If $U_{n}>u_{2}$, then individual $n$ intends to own two or more cars after the age of 65 . Here, $u_{1}, u_{2}$ are cutoffs and $u_{1}<u_{2}$.

\subsection{MNL model}

The influencing factors of mode choice are analysed based on an MNL model. In the MNL model, an individual is always assumed to choose a transport mode with the maximum utility. Generally, people who intend to own private cars are more likely to perform their trips by driving after the age of 65; therefore, the utility of owning private cars after the age of $65 U_{n}$ should be considered here. Consequently, the utility of transport mode $i$ is described as

$U_{\text {in }}=\boldsymbol{w}^{\prime} \boldsymbol{Z}_{\boldsymbol{i}}+\boldsymbol{\theta}^{\prime} \boldsymbol{X}_{\boldsymbol{n}}+\alpha f\left(U_{n}\right)+\boldsymbol{\varepsilon}_{\text {in }}$

where $U_{i n}$ is the utility of transport mode $i$ for individual $n ; \boldsymbol{Z}_{\boldsymbol{i}}$ denotes the vector of attributes of transport mode $i$; thus, it varies across the alternatives; $\boldsymbol{X}_{\boldsymbol{n}}$ is defined above; $f\left(U_{n}\right)$ is the function of $U_{n} ; \boldsymbol{w}$ and $\boldsymbol{\theta}$ are the vectors of coefficients to be estimated; $\alpha$ denotes the coefficient of $f\left(U_{n}\right)$.

Generally speaking, owning private cars can greatly benefit the elderly over the age of 65; thus, function $f\left(U_{n}\right)$ should be positive. Furthermore, the increase in the number of household cars can lead to a big increase in the probability of driving. As a result, an exponential function is introduced in the utility function. According to Equation $1, U_{n}$ is a random variable, and then function $f\left(U_{n}\right)$ should be written as

$$
f\left(U_{n}\right)=e^{E\left[U_{n}\right]}
$$


where $E\left[U_{n}\right]$ means the expected value of $U_{n}$. It is assumed that $\varepsilon_{n}$ in Equation 1 follows the logistic distribution. Thus, the expected value of $U_{n}$ equals $V_{n}$, that is, $E\left[U_{n}\right]=V_{n}$.

Here, $\varepsilon_{i n}$ denotes the IID error term which varies across the alternatives and individuals. The error term $\varepsilon_{i n}$ is assumed to follow type I extreme value (Gumbel) distribution.

Consequently, the probability that individual $n$ chooses mode $i$ is given by

$$
P_{n}(i)=\frac{e^{\boldsymbol{w}^{\prime} \boldsymbol{Z}_{\boldsymbol{i}}+\boldsymbol{\theta}^{\prime} \boldsymbol{X}_{\boldsymbol{i n}}+\alpha e^{V_{n}}}}{\sum_{j=1}^{J} e^{\boldsymbol{w}^{\prime} \boldsymbol{Z}_{\boldsymbol{j}}+\boldsymbol{\theta}^{\prime} \boldsymbol{X}_{\boldsymbol{j} \boldsymbol{n}}+\alpha e^{V_{n}}}}
$$

where $J$ denotes the choice set.

\section{SURVEY AND DATA}

In order to investigate the travel demands of the future elderly, an SP survey was conducted in Beijing. Beijing is China's political, cultural, industrial and financial centre covering a land area of $16,410.54 \mathrm{~km}^{2}$ and with 21.7 million inhabitants. In 2015, the percentage of the population aged 65 or above reached up to $10.3 \%$. The transportation system in Beijing is much more perfect and advanced than in most other cities in China; thus, the transport policies applied for the aging society in Beijing will provide a strong demonstration effect to other cities.

The future elderly are mostly young and middle-aged people at present. Therefore, residents aged 18 years or above in Beijing are selected as the objects of this survey. The survey was conducted through the website wjx.sojump.com (SOJNMP) which is a professional online survey site. SOJNMP has been chosen for two reasons. Firstly, with steady increase of the network users, web-based survey becomes convenient and efficient. The site of SOJNMP can be visited via a computer, mobile phone or other information terminals. Secondly, SOJNMP possesses around 2.6 million volunteer respondents. According to the request of each survey, SOJNMP can randomly pick up the samples who meet the requirements from its respondent database and invite them to participate in the corresponding survey.

The questionnaire consisted of three parts. The first part investigated the Willingness of Car Ownership at household level after they are 65 years old (WCO65years). Respondents were asked how many private cars they intend to own at a household level after the age of 65. Three alternatives could be selected: no car, one car and two or more cars.

The second part was designed to investigate the travel demands after the age of 65 , such as trip purposes, trip generation rates, departure time, and transport modes for different purposes. Only the modes for shopping trips over $3 \mathrm{~km}$ were taken into consideration in this paper. Transport modes included driving a car, public transport, taxis with Dial-a-Ride service, and others such as bicycle, car passenger, etc. Influencing variables consisted of parking fees, access time to bus stops, and waiting time for taxis. Each variable had 3 levels. Table 1 shows the influencing variables and the corresponding levels. An orthogonal design was used, and there were 9 scenarios altogether in this part $(T=9)$.

The third part was about personal characteristics (e.g. age, gender, marital status, educational background, driving license, number of private cars, monthly income, etc.). Due to the relationship between the attitudes towards each transport mode and mode choice behaviours [20], the information about the attitudes towards public transport services and driving were also collected in this part. The attitudes towards public transport services included two aspects: (a) satisfaction with the local public transport; and (b) convenience of local public transport. The alternatives used a five-point Likert-type scale from 'strongly dissatisfied/inconvenient' (1 point) to 'strongly satisfied/ convenient' (5 points). The attitudes towards driving included four aspects: (a) liking to drive; (b) driving a car is a relatively safe mode of transport; (c) driving a car is a convenient and free mode of transport; and (d) driving is tiring. Respondents were asked to assess by using a five-point scale from 'strongly disagree' (1 point) to ‘strongly agree' (5 points).

Table 1 - Description of variables and corresponding levels

\begin{tabular}{||c|c|c|c||}
\hline \hline & Parking fees & $\begin{array}{c}\text { Access time } \\
\text { to bus stops }\end{array}$ & $\begin{array}{c}\text { Waiting time } \\
\text { for taxis }\end{array}$ \\
\hline \hline Level 1 & RMB 2/h & 3 minutes & 10 minutes \\
\hline Level 2 & RMB 5/h & 5 minutes & 20 minutes \\
\hline Level 3 & RMB 10/h & 8 minutes & 30 minutes \\
\hline
\end{tabular}

A total of 1,097 respondents answered this questionnaire in about three weeks. Generally, the work and life status of people under the age of 30 are mostly not "steady"; therefore, to avoid unreliability of the results, only respondents aged 30 or above were taken into consideration here. Finally, after removing uncompleted questionnaires, 853 valid ones were used for further analysis $(N=853)$.

Table 2 presents the descriptive statistics for some key variables in the questionnaires. It can be seen that $92.5 \%$ of respondents intend to own private cars after the age of 65 , although the car ownership of the elderly is very low in Beijing at present. The percentages of male and female respondents are $51.8 \%$ and $48.2 \%$, respectively. This gender ratio is approximately equal to the results of the sixth national population census in 2010 which shows that males account for $51.6 \%$ of residents in Beijing [21]. It is implied that the sample is representative to a certain degree. 
Table 2 - Descriptive statistics of some key variables

\begin{tabular}{|c|c|c|c|}
\hline \multicolumn{2}{|c|}{ Variables } & \multirow{2}{*}{$\begin{array}{c}\text { Total number } \\
64\end{array}$} & \multirow{2}{*}{$\begin{array}{c}\text { Proportion [\%] } \\
7.5 \%\end{array}$} \\
\hline \multirow{3}{*}{ wC0-65years } & No car & & \\
\hline & One car & 470 & $55.1 \%$ \\
\hline & Two or more cars & 319 & $37.4 \%$ \\
\hline \multirow{6}{*}{ Age } & $30 \sim 34$ & 272 & $31.9 \%$ \\
\hline & $35 \sim 39$ & 227 & $26.6 \%$ \\
\hline & $40 \sim 44$ & 144 & $16.9 \%$ \\
\hline & $45 \sim 49$ & 84 & $9.8 \%$ \\
\hline & $50 \sim 54$ & 52 & $6.1 \%$ \\
\hline & $54+$ & 74 & $8.6 \%$ \\
\hline \multirow{2}{*}{ Gender } & Male & 442 & $51.8 \%$ \\
\hline & Female & 411 & $48.2 \%$ \\
\hline \multirow{2}{*}{ Marital status } & Couple & 755 & $88.5 \%$ \\
\hline & Single & 98 & $11.5 \%$ \\
\hline \multirow{3}{*}{ Education } & Below bachelor & 141 & $16.5 \%$ \\
\hline & Bachelor & 494 & $57.9 \%$ \\
\hline & Master or above & 218 & $25.6 \%$ \\
\hline \multirow{2}{*}{ Driving license } & No & 168 & $19.7 \%$ \\
\hline & Yes & 685 & $80.3 \%$ \\
\hline \multirow{3}{*}{ Number of household cars at present } & No car & 168 & $19.7 \%$ \\
\hline & One car & 593 & $69.5 \%$ \\
\hline & Two or more cars & 92 & $10.8 \%$ \\
\hline \multirow{3}{*}{ Housing location } & Within $2^{\text {nd }}$ Ring $(12 R)$ & 105 & $12.3 \%$ \\
\hline & Between $2^{\text {nd }}$ and $5^{\text {th }}$ Ring (B2 5R) & 434 & $50.9 \%$ \\
\hline & Outside $5^{\text {th }}$ Ring (05R) & 314 & $36.8 \%$ \\
\hline
\end{tabular}

Pension is generally the most important income source of the elderly. Thus, this variable should be considered. The pension is determined based on the accumulate payment time, payment wage, local worker average wage, amount of the individual account, etc. Here, the future pension of each respondent was estimated based on the following three hypotheses:

1) The payment wage of each respondent is equal to the mean of their income range.

2) The local worker average wage takes the average wage of Beijing worker in 2015 [22].

3) The accumulate payment time of all respondents are the same and equal to 40 years.
The final estimation result is shown in Figure 1. Nearly half of the respondents' pensions are between RMB 4,000 and 6,000.

Furthermore, Table 3 shows descriptive statistics for attitudes towards different transport mode. It is clear that the respondents have a greater appreciation of local public transport, especially about the convenience of local public transport. But only 64 respondents stated that they would not own any private car when they are older than 65, and most of them prefer to own private cars after the age of 65 . This may be attributed to two reasons. One is the special demands of the elderly which local public transport at present

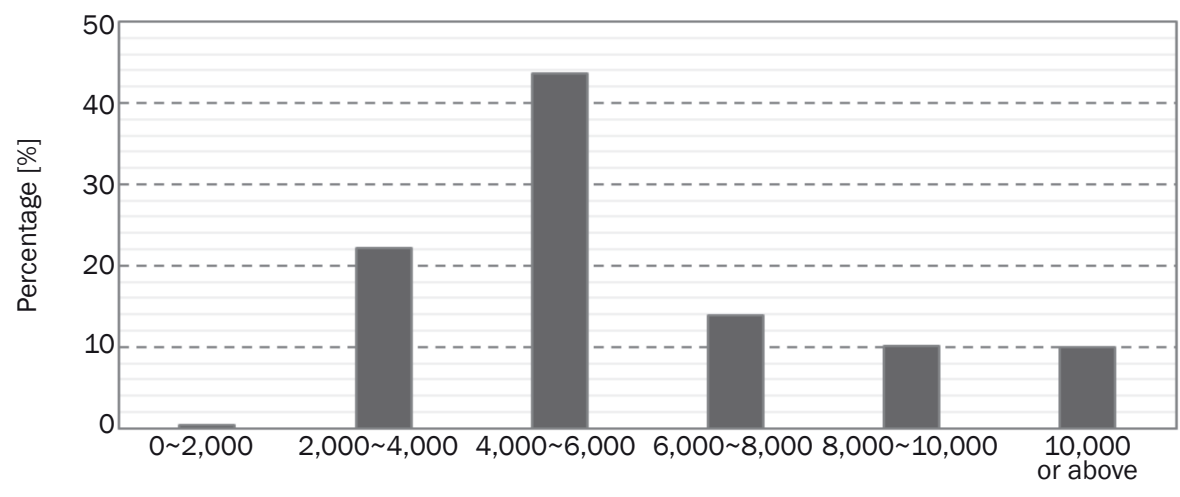

Figure 1 - The estimated pension income of the valid respondents [RMB] 
Table 3 - Descriptive statistics of attitudes towards different transport modes

\begin{tabular}{||l|c|c||}
\hline Variables & Mean & $S E$ \\
\hline Convenience of local public transport & 3.37 & 0.96 \\
\hline $\begin{array}{l}\text { Satisfaction with the local public } \\
\text { transport }\end{array}$ & 3.12 & 0.89 \\
\hline Liking to drive & 3.36 & 0.86 \\
\hline $\begin{array}{l}\text { Driving a car is a relatively safe mode of } \\
\text { transport }\end{array}$ & 3.24 & 0.82 \\
\hline $\begin{array}{l}\text { Driving a car is a convenient and free } \\
\text { mode of transport }\end{array}$ & 3.88 & 0.79 \\
\hline Driving is tiring & 3.00 & 0.92 \\
\hline
\end{tabular}

is unable to satisfy. This will be demonstrated further in the next Section. The other is associated with their preference for private cars. As shown in Table 3, they have a much greater appreciation for driving a car, except for $(d)$ driving is tiring.

Finally, the questionnaire's reliability and validity analysis were conducted with SPSS. The Cronbach's alpha coefficient is 0.709 , which confirms the internal consistency of this questionnaire. The Kaiser-Meyer-Olkin value is 0.702 , which demonstrates that this questionnaire is of good structure validity. The results show that the questionnaire designed in this study has acceptable reliability and validity.

\section{ESTIMATION RESULTS}

\subsection{Ordered logit model for Car ownership of the future elderly}

It is already revealed that most respondents intend to own private cars after they are 65 years old. But the underlying factors that influence their willingness remain to be investigated. To this end, an ordered logit model has been used to analyse the influencing factors on car ownership of the future elderly.

Table 4 shows the relationship between WCO65years and age. Here, the 95\% confidence level $(\rho>0.05)$ which corresponds to $t$-statistics of 1.96 is used. It can be seen that there is no significant difference among people below the age of 45 , but a significant difference emerges between people aged 30 34 and those aged 45 or above. Specifically, the effect of change in age on the probabilities to own private cars after the age of 65 is shown in Figure 2. With the increase of age, people's propensities to own no car or one private car after the age of 65 increase significantly, particularly for people who are aged 50 or above. However, their propensities to own two or more cars decrease dramatically. It means that all the people have higher propensities to own private cars after the age of 65 . The younger the people are, the more likely they are to own private cars after the age of 65 .

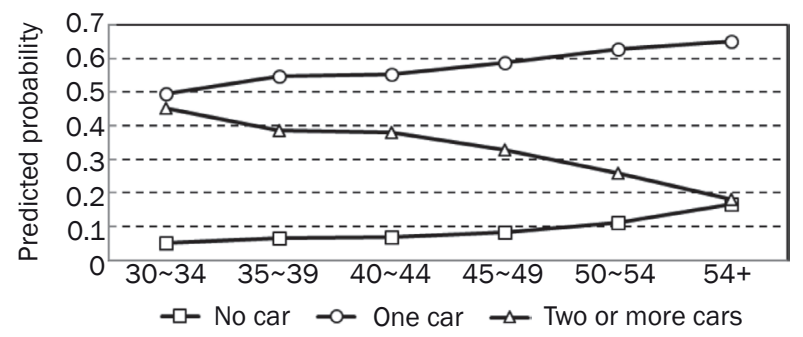

Figure 2 - Effects of change in age on predicted probabilities

In addition, the relationships with the number of household cars at present and pension income are estimated (see Table 5). Increase of the number of household cars will result in an increase in WC0-65years. Probably because it is not possible for people who own private cars at present to give up their cars after the age of 65 , due to the higher depreciation and convenience of cars. Moreover, people with higher pension income have higher propensities to own private cars after the age of 65. But there is no significant difference between those with pension income less than 8,000 . It is implied that RMB 8,000 is a cut-off point, and as long as the residents in Beijing have pension income above 8,000 in the future, they have relatively higher propensities to own private cars after the age of 65 .

Table 4 - Estimation result for the relationship between WCO-65years and age

\begin{tabular}{||c|c|c|c|c|c|c|c||}
\hline Age & Coefficient & $S E$ & $t$ & Age & Coefficient & $S E$ & $t$ \\
\hline \hline $30 \sim 34$ & Reference & & & $45 \sim 49$ & -0.5186 & 0.2543 & -2.10 \\
\hline $35 \sim 39$ & -0.2669 & 0.1778 & -1.50 & $50 \sim 54$ & -0.8658 & 0.2988 & -2.90 \\
\hline $40 \sim 44$ & -0.2963 & 0.2018 & -1.47 & $54+$ & -1.3212 & 0.2698 & -4.90 \\
\hline
\end{tabular}

Table 5 - Estimation result for the relationships with the number of cars and pension income

\begin{tabular}{||c|c|c|c|c|c|c|c||}
\hline \hline Number of cars & Coefficient & $S E$ & $t$ & Pension income & Coefficient & $S E$ & $t$ \\
\hline \hline No & -1.1058 & 0.1978 & -5.59 & $0 \sim 4,000$ & -0.2858 & 0.1715 & -1.67 \\
\hline One & Reference & & & $4,000 \sim 8,000$ & Reference & & \\
\hline Two or more & 1.6609 & 0.2535 & 6.55 & 8,000 or above & 0.4222 & 0.1719 & 2.46 \\
\hline
\end{tabular}


Table 6 - Estimation result for the relationships between WCO-65years and other factors

\begin{tabular}{||c|c|c|c||c|c|c|c||}
\hline \hline Variable & Coefficient & $S E$ & $t$ & Education & Coefficient & $S E$ & $t$ \\
\hline \hline \multirow{2}{*}{$\begin{array}{c}\text { Gender } \\
\text { (1-Male) }\end{array}$} & \multirow{3}{*}{0.2750} & \multirow{3}{*}{0.1360} & \multirow{2}{*}{2.02} & Below bachelor & -0.3682 & 0.1646 & -2.24 \\
\cline { 5 - 8 } & & & & Bachelor & Reference & & \\
\cline { 5 - 8 } & & & & Master or above & 0.6533 & 0.1864 & 3.50 \\
\hline
\end{tabular}

Other influencing factors are also investigated respectively (see Table 6). Compared with women, men have higher propensities to own private cars after the age of 65. People with higher educational degree are more likely to own private cars after the age of 65 . This may be due to higher trip generation rates of highly educated people [23,24], because owning private cars is always convenient for travelling.

In conclusion, the analysis above has revealed that age produces a significant effect on WCO-65years, and the elderly of the future have higher propensities to own private cars. In addition, it has been also found that pension income, gender, education and car ownership at present are the significant factors that influence WCO-65years. Consequently, the final ordered logit model for WCO-65years should be built with these variables.

\subsection{MNL model for Mode choices of the future elderly}

As analysed above, the future elderly in Beijing have higher propensities to own private cars. Then their car usage is investigated based on an MNL model. Obviously, $U_{n}$ is considered as a variable influencing the mode choices of the future elderly. Therefore, the estimation should take a two-phase approach: the estimation of the ordered logit model for the car ownership, and the estimation of the MNL model for the mode choice behaviours. Here, the maximum-likelihood procedure is applied and the results are presented in Table 7. In the MNL model, no attribute or characteristic is included in the alternative "others", and its utility equals zero. Finally, all the variables with lower than 5\% significance level are retained. A few of variables with significance levels higher than $5 \%$ are also retained due to the expected sign and their importance to transport policies.

As expected, parking fees, access time to bus stops and waiting time for taxis have significant and negative effects. Among them, parking fees have a greater effect on the mode choices of the future elderly. It is implied that in comparison with time, the future elderly seem to care more about travel cost.

Age is statistically significant. It is clear that age has not only direct effect on the propensity to drive a car after the age of 65, but also the indirect influence on it by affecting WCO-65years. Compared with those aged 30 34, the combined effects of other age groups can be calculated as
$C E_{\text {age }}=\beta_{\text {age }}-\alpha \cdot\left(1-e^{\theta_{\text {age }}}\right)$

where $C E_{\text {age }}$ denotes the combined effect of each age group; Parameters $\beta_{\text {age }}$ and $\theta_{\text {age }}$ are the coefficients in car ownership model and mode choice model, respectively. The results are shown in Table 8.

It is clear that people aged 50 54 have the highest propensities to make use of cars after the age of 65 . This may be explained by the fact that these groups have just experienced the rapid growth of the urban motorization. Compared with people below the age of 50 , their novelty of driving will not wear off when they are older than 65 . In comparison to those aged 55 or above, they have relatively healthier bodies. Therefore, people aged 50 54 are more likely to perform their trips by driving after the age of 65. It means that about ten years later the elderly in Beijing will become very dependent on private cars. For those below the age of 50 , younger people are more likely to make use of private cars after the age of 65 . Besides, in contrast to driving a car, people aged 40 44 prefer to make use of taxis after the age of 65 .

The influences of gender, marital status, educational background, housing location and income are also significant. Gender has the indirect and positive effect on driving a car. Men are more likely to make use of private cars after the age of 65 , and they have lower propensities to take taxis. Consistent with the relationship between WCO-65years and education, people who are highly educated have higher propensities to drive a car after the age of 65 . Housing location significantly influences the propensity to make use of public transport or taxis, and people who live near the urban centre are more likely to perform their trips by public transport or taxis after the age of 65. It also implies that people who live near the urban centre have lower propensities to drive a car after the age of 65 , because the sum of all mode choice probabilities should be $100 \%$. As expected, people with higher income have relatively higher propensities to make their trips by driving or taxis. Furthermore, people who have a driving license prefer to make use of private cars after the age of 65 . In addition, the utility of WCO-65years has a positive and significant effect on the propensity of driving.

It can be seen that the attitudes towards each transport mode significantly influence the mode choice behaviours of the future elderly. In order to check whether the current model is reasonable and reliable, the five-point Likert-type scale for the attitudes towards each transport mode is simplified into the three-point 
Table 7 - Multi-logit model for mode choices of the future elderly

\begin{tabular}{|c|c|c|c|c|c|c|c|}
\hline \multirow{2}{*}{\multicolumn{2}{|c|}{ Variables }} & \multicolumn{2}{|c|}{ Driving a car } & \multicolumn{2}{|c|}{ Public transport } & \multicolumn{2}{|c|}{ Taxis } \\
\hline & & Coefficient & $t$ & Coefficient & $t$ & Coefficient & $t$ \\
\hline \multicolumn{2}{|l|}{ Constant } & -0.2409 & -1.80 & 0.6967 & 8.26 & -0.6616 & -4.72 \\
\hline \multicolumn{2}{|l|}{$\alpha$} & 0.0609 & 4.55 & & & & \\
\hline \multicolumn{2}{|l|}{ Parking fees } & -0.1274 & -12.74 & & & & \\
\hline \multicolumn{2}{|l|}{ Access time to bus stops } & & & -0.0467 & -4.09 & & \\
\hline \multicolumn{2}{|l|}{ Waiting time for taxis } & & & & & -0.0188 & -3.96 \\
\hline \multirow{6}{*}{ Age } & $30 \sim 34$ & Reference & & & & Reference & \\
\hline & $35 \sim 39$ & -0.1370 & -1.64 & & & 0.1397 & 1.44 \\
\hline & $40 \sim 44$ & -0.1123 & -1.13 & & & 0.4102 & 3.81 \\
\hline & $45 \sim 49$ & -0.4871 & -3.85 & & & & \\
\hline & $50 \sim 54$ & 0.3883 & 2.91 & & & & \\
\hline & $54+$ & -0.1781 & -1.39 & & & -0.8284 & -3.87 \\
\hline \multicolumn{2}{|l|}{ Gender (1-Male) } & & & & & -0.1968 & -2.50 \\
\hline \multicolumn{2}{|l|}{ Marital status (1-Single) } & & & -0.1958 & -2.30 & 0.3435 & 2.66 \\
\hline \multirow{3}{*}{ Pension income } & RMB 0 4,000 & -0.6210 & -5.69 & -0.1814 & -2.63 & -0.4194 & -3.66 \\
\hline & RMB 4,000 8,000 & Reference & & Reference & & Reference & \\
\hline & RMB 8,000 or above & 0.3048 & 3.93 & & & 0.1749 & 1.70 \\
\hline \multirow{3}{*}{ Education } & Below bachelor & -0.3976 & -4.39 & -0.2593 & -3.95 & -0.4875 & -4.37 \\
\hline & Bachelor & Reference & & Reference & & Reference & \\
\hline & Master or above & & & -0.2005 & -2.80 & -0.1604 & -1.42 \\
\hline \multirow{3}{*}{ Housing location } & I2R & & & 0.3879 & 4.75 & 0.2493 & 1.78 \\
\hline & B2 5R & & & 0.2231 & 4.03 & 0.3729 & 4.06 \\
\hline & 05R & & & Reference & & Reference & \\
\hline \multicolumn{2}{|l|}{ Driving license (1-No) } & -0.8150 & -6.94 & & & & \\
\hline \multirow{3}{*}{$\begin{array}{l}\text { Satisfaction with the local } \\
\text { public transport }\end{array}$} & Dissatisfied & & & -0.2278 & -3.61 & & \\
\hline & Neutral & & & Reference & & & \\
\hline & Satisfied & & & 0.2846 & 5.29 & & \\
\hline \multirow{3}{*}{ Liking to drive } & Dislike & -0.2922 & -2.14 & & & & \\
\hline & Neutral & Reference & & & & & \\
\hline & Like & 0.1922 & 2.57 & & & & \\
\hline & Disagree & -0.3570 & -2.96 & & & & \\
\hline Driving a car is a relatively & Neutral & Reference & & & & & \\
\hline & Agree & 0.7277 & 9.80 & & & & \\
\hline & Disagree & -0.5710 & -2.59 & & & & \\
\hline Driving a car is a convenient & Neutral & Reference & & & & & \\
\hline & Agree & 0.5794 & 5.56 & & & & \\
\hline $\begin{array}{l}\text { Systematic component } V_{m} \\
\text { of WCO-65years }\end{array}$ & Gender(1-Male) & 0.3893 & 2.69 & & & & \\
\hline & $30 \sim 34$ & Reference & & & & & \\
\hline & 35 39 & -0.3087 & -1.60 & & & & \\
\hline & $40 \sim 44$ & -0.3488 & -1.58 & & & & \\
\hline Age & $45 \sim 49$ & -0.6438 & -2.43 & & & & \\
\hline & $50 \sim 54$ & -1.0837 & -3.41 & & & & \\
\hline & $54+$ & -1.5392 & -5.49 & & & & \\
\hline & Below bachelor & & & & & & \\
\hline Education & Bachelor & Reference & & & & & \\
\hline & Master or above & 0.6451 & 3.22 & & & & \\
\hline & No & -1.2521 & -6.25 & & & & \\
\hline Number of household cars & One & Reference & & & & & \\
\hline & Two or more & 1.8150 & 6.88 & & & & \\
\hline Number of observations $(N \cdot T)$ & & & 7,677 & & & & \\
\hline Mean log likelihood of null m & odel & & $-10,642$ & 582 & & & \\
\hline Mean log likelihood of full mo & del & & $-9,063.2$ & & & & \\
\hline Likelihood ratio index $\left(\rho^{2}\right)$ & & & 0.1484 & & & & \\
\hline Adjusted likelihood ratio inde & $x\left(\overrightarrow{\rho^{2}}\right)$ & & 0.1445 & & & & \\
\hline
\end{tabular}


Table 8 - Combined effects of all age groups in the mode choice model

\begin{tabular}{||c|c|c|c|c|c|c|c|}
\hline Age & $\beta_{\text {age }}$ & $\theta_{\text {age }}$ & $C E_{\text {age }}$ & Age & $\beta_{\text {age }}$ & $\theta_{\text {age }}$ & $C E_{\text {age }}$ \\
\hline \hline $30 \sim 34$ & Reference & & & $45 \sim 49$ & -0.4871 & -0.6438 & -0.5160 \\
\hline $35 \sim 39$ & -0.1370 & -0.3087 & -0.1532 & $50 \sim 54$ & 0.3883 & -1.0837 & 0.3480 \\
\hline $40 \sim 44$ & -0.1123 & -0.3488 & -0.1302 & $54+$ & -0.1781 & -1.5392 & -0.2259 \\
\hline
\end{tabular}

Likert-type scale. With respect to the attitudes towards public transport, improving local public transport services and raising passengers' satisfaction influence positively the propensity to make use of public transport.

Compared with the reference group who are neutral with the attitude that driving is a relatively safe mode of transport, people who agree with this attitude are more likely to perform their trips by driving after the age of 65 . On the contrary, people who disagree with this attitude have lower propensities to drive a car. Meanwhile, the former effect is more than two times greater than the latter. This means that the improvement in the driving safety can attract a large number of the future elderly, but deterioration in the driving safety may not significantly reduce people's propensities to make use of driving after the age of 65 .

In conclusion, the future elderly in Beijing will depend more on driving a car. But the improvement of local public transport services can be helpful to increase the future elderly's propensities to make use of public transport. And deterioration in the driving safety may not reduce significantly their propensities to drive a car.

\section{EFFECT OF UNCERTAINTY}

When the coefficients in the MNL model have been estimated, the probability of each transport mode can be calculated according to Equation 4. Since the statements of the current young and middle-aged residents in Beijing may not fully reflect their actual behaviours when they are older than 65 , uncertainty exits in their statements, especially for younger people. Consequently, the final probability should be calculated by considering this uncertainty.

In order to characterize the uncertainty in the statements of respondents, the concept of reliability is introduced. Here, the reliability in the stated preference for mode $i$ is defined as the conditional probability of an event that individual $n$ chooses mode $i$ actually when they are older than 65 , given that the individual stated they would choose mode $i$ after the age of 65 . Since car dependence of the future elderly is investigated in this paper, only the driving is taken into consideration here. Let $A$ be the event that individual $n$ stated they would choose driving after the age of 65 , and $B$ denote that individual $n$ chooses driving actually after the age of 65 . Then the reliability in the stated preference for driving of individual $n$ can be expressed as $P_{n}(B \mid A)$, and the reliability in the stated preference for not-driving equals $P_{n}(\bar{B} \mid \bar{A})$. Here $\bar{A}$ means "not $A$ ", and so does $\bar{B}$. Consequently, according to the whole probability formula, the predicted probability of choosing driving actually after the age of 65 , or the probability of driving for short, is obtained as

$$
P_{n}=P_{n}(A) \cdot P_{n}(B \mid A)+\left(1-P_{n}(A)\right) \cdot\left(1-P_{n}(\bar{B} \mid \bar{A})\right)
$$

where $P_{n}$ is the probability of driving of individual $n$; $P_{n}(A)$ is the probability of the event A which can be calculated by Equation 4.

Generally, the younger the individual is, the lower becomes the reliability in their statements. Here, it is assumed that the reliability drops by $q$ for every five years decreased from the individual's age. As a result, let $P(B \mid A)$ and $P(\bar{B} \mid \bar{A})$ for an individual aged 55 or above equal $p_{1}$ and $p_{2}$, respectively, and then for an individual aged 50 54, these two reliabilities can be calculated as: $P(B \mid A)=(1-q) \cdot p_{1}$ and $P(\bar{B} \mid \bar{A})=(1-q) \cdot p_{2}$. Similarly, the reliabilities for other age groups can be obtained with a recursive method.

Assuming all the variables in the MNL model expected age are fixed (Parking fees are RMB 5/h, access time to bus stops is 5 minutes, waiting time for taxis equals 20 minutes, male, single, pension income is $\mathrm{RMB} 4,000 \sim 8,000$, bachelor degree, housing location is B2 5R, holding a driving license, household car number is one, satisfied with local public, like driving, and agree with other two attitudes towards driving), the probability of driving with different $p_{1}, p_{2}$ and $q$ is presented in Figure 3. It is clear that although parameters $p_{1}, p_{2}$ and $q$ have significant effects on the probability of driving among the future elderly, the relationship between the probability of driving and age does not change much, and younger people have higher propensities to make use of private cars after the age of 65.

\section{DICUSSION AND CONCLUSION}

With the increase of the elderly in the world, considerable attention has been given to the travel behaviours of the elderly. However, the studies about the travel demands among the elderly, especially the future elderly, are relatively scarce. To fill this research gap and get insight into the travel demands of the elderly, this paper investigates the car ownership and usage of the future elderly by surveying the young and 


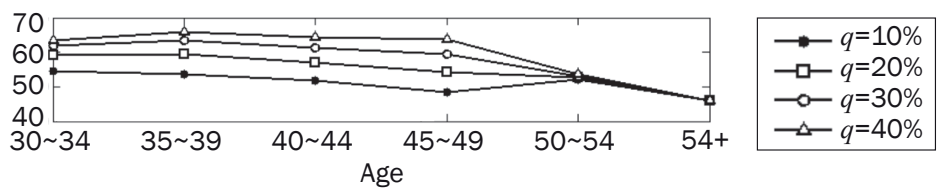

a) Probability of driving [\%], $P_{1}=80 \%, P_{2}=70 \%$

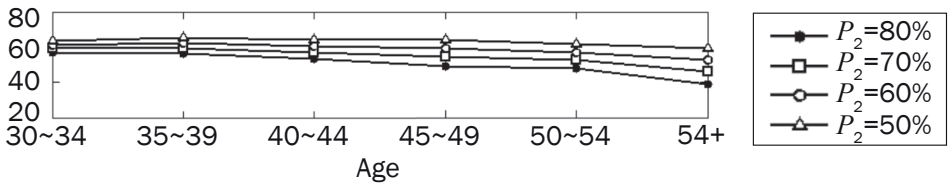

b) Probability of driving [\%], $P_{1}=80 \%, q=20 \%$

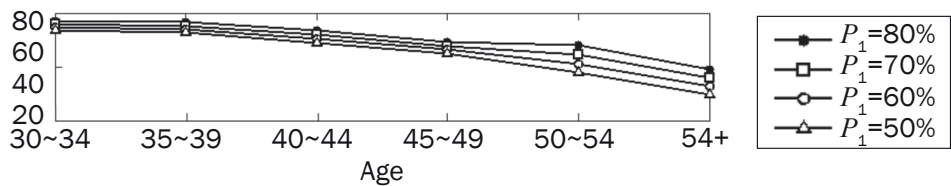

c) Probability of driving [\%], $P_{2}=80 \%, q=20 \%$

Figure 3 - Probability of driving with different $p_{1}, p_{2}$ and $q$

middle-aged people in Beijing at present. Also, the influencing factors are analysed based on the discrete model.

One of the main outcomes of this paper is that younger people have higher propensities to own private cars and to make use of driving after the age of 65. This implies that the future elderly in Beijing will become more dependent on private cars and private cars will play an important role in the elderly's mobility. Such findings have been presented in previous studies [7-11] concerning the older Americans, the European elderly, etc. Another key finding is that in addition to parking fees, access time to bus stops, waiting time for taxis, personal characteristics are also significantly associated with both car ownership and usage of the future elderly. Among these factors, the effect of parking fees is negative and greater than access time to bus stops or waiting time for taxis. This finding was also found in reference [17]. Men have higher propensities to make use of private cars after the age of 65 This result is consistent with the findings of references $[12,25]$. People with higher income are more likely to make their trips by driving or taxi. This finding was also supported by references $[12,17]$. Above all, there are many common characteristics between the travel demands of the future elderly in Beijing and the revealed travel behaviours of the elderly in Western counties.

Increase in the probability of driving among the future elderly will make traffic problems, such as traffic congestion and traffic safety risk, more serious [26]. As the population is continuously aging, Beijing can learn from Western counties' experience, and improve the transport infrastructure to meet the needs of the growing numbers of the elderly drivers. Car manufacturers are trying to design and provide advanced cars (cars with driver assistance system, autonomous vehicles, etc.) for the elderly drivers [27]. Furthermore, the rules and regulations about how the elderly drivers renew their licenses as well as how the elderly apply for driving licenses, should be established and improved.

In addition, the future elderly are heterogeneous in their travel demands. Although they become more dependent on private cars, certain sub-groups may prefer other transport modes. Therefore, in order to alleviate traffic congestion, alternatives to driving should be provided. The high-service public transport that offers discounted fares to the elderly is worth pursuing. Other new intelligent transportation systems (like Diala-Ride, PlusBus, ShopMobility, etc.) that can shorten the waiting time also deserve consideration in this information era.

Future research of the travel demands among the future elderly would be expanded to: (1) trip generation rates, travel distance and so on; and (2) investigating the travel demands of the future elderly in other cities. There are many indicators used to measure the travel demands, such as trip generation rates, travel distance, mode choices, etc. This paper has only explored one dimension. Investigating the travel demands of the future elderly from other dimension is also critical. Moreover, expanding our investigation to other cities can help us to compare the differences and summarize the future development trend of the travel demands among the elderly in the entire China. Then more references can be provided for the aging society when planning urban transportation systems and making transport policies. 


\section{ACKNOWLEDGEMENT}

We would like to acknowledge the National Natural Science Foundation of China (No. 51578319, 51778340).

\section{菅美英, 博士研究生 1,2}

邮箱: jianmy321@163. com

石京, 教授, 博士 ${ }^{1}$

(通讯作者)

邮箱: jingshi@mail. tsinghua. edu. cn

刘昒, 博士研究生 ${ }^{1}$

邮箱: 1y3664296@126.com

1 清华大学 土木工程系

北京，中国100084

2 内蒙古大学 交通学院

呼和浩特 中国 010021

$$
\text { 未来老年人对私人小汽车的依赖性一以北京为例 }
$$

\section{摘要}

随着全球人口老龄化的加剧, 把握老年人的出行需求 变得非常重要。目前, 中国的老龄化社会正在形成, 城市 机动化进程也刚刚起步。本文的目的在于研究中国未来老 年人对私人小汽车的依赖情况。基于对北京当前中青年人 群在老年后的出行意向的SP调查数据, 采用ordered logit 模型和MNL模型, 分别对未来老年人保有小汽车和出行 方式选择行为及其相应的影响因素进行分析。在此基础 上, 本文进一步分析了调查数据的不确定性对模型结果的 影响。结果表明: 北京未来的老年人将会越来越依赖于小 汽车。具体而言, 年龄越小的中青年人群, 在老年后继续 保有小汽车和使用小汽车的意向越强烈。此外, 改善公共 交通的服务水平有助于提高未来老年人使用公共交通出行 的可能性。本文的研究结果为北京制定应对老龄化社会的 交通政策提供了重要的参考。

\section{关键词}

出行需求; 未来老年人; 保有小汽车; 出行方式选择; 影 响因素

\section{REFERENCES}

[1] Worldbank. World Development Indicators [Internet]. No date [cited 2016 May 11]. Available from: http:// data.worldbank.org.cn/indicator/SP.POP.65UP.TO.ZS

[2] OECD. Aging and Transport: Mobility Needs and Safety Issues, Organization for Economic Co-operation and Development, Paris; 2001.

[3] Regelman M, Raman J. Micro Simulation of the Elderly Population's Effect on Iran's Pedestrian's Walking Flow. Promet - Traffic \& Transportation. 2013;25(4): 331-342.

[4] Hildebrand ED. Dimensions in elderly travel behaviour: a simplified activity-based model using lifestyle clusters. Transportation. 2003; 30(3): 285-306.

[5] Siren A, Hakamies-Blomqvist L. Private car as the grand equaliser? Demographic factors and mobility in Finnish men and women aged 65+. Transportation Research Part F: Traffic Psychology \& Behaviour. 2004;7(2): 107-118.

[6] Farber S, Paez A, Mercado RG, Roorda M, Morency C. A time-use investigation of shopping participation in three Canadian cities: is there evidence of social exclusions?. Transportation. 2011;38(1): 17-44.

[7] Habib KN. An investigation on mode choice and travel distance demand of older people in the National Capital Region (NCR) of Canada: application of a utility theoretic joint econometric model. Transportation. 2015;42(1): 143-161.

[8] Rosenbloom S. Sustainability and automobility among the elderly: An international assessment. Transportation. 2001;28(4): 375-408.

[9] Collia DV, Sharp J, Giesbrecht L. The 2001 National Household Travel Survey: a look into the travel patterns of older Americans. Journal of Safety Research. 2003;34(4): 461-70.

[10] Newbold KB, Scott DM, Spinney JEL, et al. Travel behaviour within Canada's older population: a cohort analysis. Journal of Transport Geography. 2005;13(4): 340-351.

[11] Hjorthol RJ, Levin L, Sirén A. Mobility in different generations of older persons: The development of daily travel in different cohorts in Denmark, Norway and Sweden. Journal of Transport Geography. 2010;18(5): 624-633.

[12] Schmöcker JD, Quddus MA, Noland RB, et al. Mode choice of older and disabled people: a case study of shopping trips in London. Journal of Transport Geography. 2008;16(4): 257-267.

[13] Zhang Z, Mao BH, Liu MJ, et al. An Analysis of Travel Patterns of the Elders in Beijing. Journal of Transportation Systems Engineering \& Information Technology. 2007;7(6): 11-20.

[14] Kim S, Ulfarsson GF. Travel Mode Choice of the Elderly: Effects of Personal, Household, Neighborhood, and Trip Characteristics. Transportation Research Record: Journal of the Transportation Research Board. 2004;1894(1894).

[15] Moniruzzaman M, Páez A, Habib KMN, et al. Mode use and trip length of seniors in Montreal. Journal of Transport Geography. 2013;30(30): 89-99.

[16] Su F, Bell MGH. Transport for older people: Characteristics and solutions. Research in Transportation Economics. 2009;25(1): 46-55.

[17] Su F, Schmöcker JD, Bell MGH. Mode choice of older people before and after shopping. Journal of Transport \& Land Use. 2007;2(1): 29-46.

[18] Hensher DA. Stated preference analysis of travel choices: the state of practice. Transportation. 1994;21(2): 107-133.

[19] Train KE. Discrete Choice Methods with Simulation. London: Cambridge University Press; 2009.

[20] Haustein S. Mobility behavior of the elderly: an attitude-based segmentation approach for a heterogeneous target group. Transportation. 2012;39(6): 1079-1103.

[21] National Bureau of Statistics of China. Tabulation on the 2010 Population Census of the People's Republic of China [Internet]. 2015 [cited 2016 Apr 21]. Available from: http://www.stats.gov.cn/tjsj/ndsj/

[22] Beijing municipal human resources and social security bureau [image on the Internet]. 2012 [cited 2016 May 15]. Available from: http://www.bjrbj.gov.cn/bmfw/

[23] Evans EL. Influences on Mobility Among Non-Driving Older Americans. Transportation Research Circular. Issue E-C026; 2001. p. 151-168. 
[24] Berg PVD, Arentze T, Timmermans H. Estimating social travel demand of senior citizens in the Netherlands. Journal of Transport Geography. 2011;19(2): 323-331.

[25] Van den Berg P, Arentze T, Timmermans H. Estimating social travel demand of senior citizens in the Netherlands. Journal of Transport Geography. 2011;19(2): 323-331.
[26] Shanmugaratnam S, Kass SJ, Arruda JE. Age differences in cognitive and psychomotor abilities and simulated driving. Accident Analysis and Prevention. 2010;42(3): 802-8.

[27] Tollazzi T, Renčelj M, Rodošek V, et al. Traffic Safety of Older Drivers in Various Types of Road Intersections. Promet - Traffic \& Transportation. 2010;22(3): 193-201. 